\title{
Tissue Banking in a Regional Hospital: A Promising Future Concept? First Report on Fresh Frozen Tissue Banking in a Hospital Without an Integrated Institute of Pathology
}

\author{
Marco von Strauss und Torney • Ulrich Güller • \\ Farid Rezaeian • Philippe Brosi - Luigi Terracciano • \\ Markus Zuber
}

Published online: 26 May 2012

(c) Société Internationale de Chirurgie 2012

\begin{abstract}
Background Vital tissue provided by fresh frozen tissue banking is often required for genetic tumor profiling and tailored therapies. However, the potential patient benefits of fresh frozen tissue banking are currently limited to university hospitals. The objective of the present pilot study - the first one in the literature-was to evaluate whether fresh frozen tissue banking is feasible in a regional hospital without an integrated institute of pathology.

Methods Patients with resectable breast and colon cancer were included in this prospective study. Both malignant and healthy tissue were sampled using isopentan-based
\end{abstract}

This study was presented in part at the Annual Meeting of the Swiss Society of Surgery, Interlaken, Switzerland May 2010.

M. von Strauss und Torney · F. Rezaeian · P. Brosi ·

M. Zuber $(\bowtie)$

Department of Surgery, Cantonal Hospital Olten, Baslerstrasse 150, 4600 Olten, Switzerland

e-mail: markus.zuber@spital.so.ch

M. von Strauss und Torney

Department of Surgery, Basel University Hospital, Basel,

Switzerland

U. Güller

Division of Medical Oncology, Cantonal Hospital

St. Gallen, St. Gallen, Switzerland

F. Rezaeian

Klinik und Poliklinik für Plastische Chirurgie und

Handchirurgie, Klinikum Rechts der Isar,

Technische Universität München, Munich, Germany

L. Terracciano

Institute for Pathology, University of Basel, Basel, Switzerland snap-freezing $1 \mathrm{~h}$ after tumor resection and stored at $-80{ }^{\circ} \mathrm{C}$ before transfer to the main tissue bank of a University institute of pathology.

Results The initial costs to set up tissue banking were 35,662 US\$. Furthermore, the running costs are 1,250 US\$ yearly. During the first 13 months, 43 samples (nine samples of breast cancer and 34 samples of colon cancer) were collected from 41 patients. Based on the pathology reports, there was no interference with standard histopathologic analyses due to the sample collection.

Conclusions This is the first report in the literature providing evidence that tissue banking in a regional hospital without an integrated institute of pathology is feasible. The interesting findings of the present pilot study must be confirmed by larger investigations.

\section{Introduction}

In the age of genetic tumor profiling and tailored therapies, adequately preserved tissue for research purposes has become mandatory. In this context, researchers are frequently confronted with the limitations of formalinembedded tissue. In particular, proteomic analysis and functional description of cells is reduced in these nonvital specimens. Therefore, it is crucial to have access to vital fresh frozen tissue for basic and translational research as a growing body of scientific evidence demonstrates the beneficial effect of the technique of gene expression profiling with fresh frozen tissue of malignant tumors [1-6]. Since the late 1980s, there have been numerous reports on various methods and strategies of tissue banking; and especially over the last decade, networks for tissue banking and specimen allocation were established in Europe and the United States [7-11]. 
All of these initiatives are run by and allocated in academic institutions with integrated institutes of pathology. Therefore, the invaluable resource of tissue banking with consequent unlimited possibilities regarding further diagnostic testing, more selective treatment, and potential patient's benefit are limited to academic institutions. This is in sharp contrast to the fact that most cancer patients in European countries are treated in nonacademic, middlesized regional hospitals. Hence, it is crucial that the enormous benefits of fresh tissue banking are not limited exclusively to large academic institutions.

Therefore, the objective of the present pilot study-the first one in the literature-was to evaluate whether tissue banking is feasible in a regional hospital without an integrated institute of pathology.

\section{Patients and methods}

The study was performed in a Swiss regional hospital (approximately 11,500 inpatients per annum, 2,000 of whom are surgical inpatients) in collaboration with the Institute of Pathology at the University of Basel (Basel, Switzerland). The two hospitals are located approximately 38 miles from each other. The study outline was submitted to and approved by the joint Ethics Committee of the Canton Aargau and Solothurn in 2008.

A process of stepwise consent for specimen collection, specimen storage, and subsequent utilization for research purposes was implemented with the explicit possibility of revocation of the consent at any time by the patient.

Patients were eligible for the study if they were $\geq 18$ years, had a proven resectable cancer of the breast or colon, and were scheduled for a surgical intervention to remove the malignancy. Moreover, the minimum tumor size was set at $1 \mathrm{~cm}$ in diameter. Patients with tumors $<1 \mathrm{~cm}$ in diameter or patients with rectal cancer were not included in the present study to avoid potential interference with standard histopathologic analyses. During the standard patient education for consent during the preoperative outpatient visit about a week prior to the operation; eligible patients were informed about the possibility of fresh frozen tissue banking and its risks. Information and consent forms were handed out in advance. During the second patient encounter the day before surgery, remaining concerns and questions were clarified, and the consent form was signed by the patient.

An instructed surgical resident collected the samples within $1 \mathrm{~h}$ after tumor resection. Samples were collected from both the tumor and the surrounding healthy tissue, each sample being 3-5 $\mathrm{mm}$ in diameter. During the first five resections, a certified pathologist was present to train three exclusive surgical residents and to monitor the tissue sampling. The residents were carefully instructed about handling the resected colon and breast cancer tissues. The resected tumor specimens were macroscopically reviewed. Threads were used to mark the orientation of the specimen. Important areas for pathologic staging, such as resection margins, were left untouched-for later analysis by an experienced pathologist. Pathologists were present for all sentinel lymph node examinations for breast cancer patients. They also supervised and monitored the specimen collection during tumorectomies, which were carried out by the instructed residents.

Both samples (cancerous and healthy tissue) were prepared for deep freezing with $5 \mathrm{ml}$ of embedding solution (Tissue-Tek O.C.T.; Medite Medizintechnik AG, Nunningen, Switzerland) in a plastic tray. Freezing was performed using an Isopentan shock freezer (SnapFrost80; Medite Medizintechnik AG) in a special area in the operating theater and took 1-2 min. Samples were then placed into small polyvinyl chloride bags, labeled, coded (alphanumeric code), and stored at $-80{ }^{\circ} \mathrm{C}$ (Frykavision, $-80{ }^{\circ} \mathrm{C}$ deep freezer; MultiTemp Scientific AG, Urdorf, Switzerland). Every 6 months the collected samples were transferred on carbon dioxide snow to the Institute of Pathology at the University of Basel.

Data were recorded prospectively, including the patient's age, sex, primary diagnosis, co-morbidities, TNM staging and grading, carcinoembryonic antigen (CEA) titer (in those with colon cancer), and the patients medications at the time of sample collection. The standard histopathologic reports were reviewed for potential interference with the sample collection. In case of suspected interference, a review of the frozen tissue samples would have been possible. However, this issue never occurred during the present pilot study.

Follow-up data included type of adjuvant treatment, surgical and nonsurgical complications, date of recurrence, and date of death. The data were reversibly anonymized.

Project investment and running costs were prospectively monitored, and the costs per sample were calculated.

\section{Results}

The age of the patients at time of sampling ranged from 55 to 88 years (median 77.5 years). Overall, tissue of 16 men and 16 women with diagnosed colon malignancies or highgrade dysplastic lesions and nine women with diagnosed breast cancer were sampled.

The median number of co-morbidities was 2 with a range from 0 to 6 . In all, 16 patients $(16 / 41 ; 39 \%$ of all patients) had only one or no co-morbid condition.

During the first 13 months, 43 samples were collected from 41 patients. Overall, 45 patients were operated on 
over the pilot study period due to malignancies of the colon and breast. Three colon tumors failed to be collected in the context of emergency operations and one breast cancer due to human failure. Consequently, $91 \%$ of the patients were correctly sampled (41/45).

Altogether, nine samples of breast tumors and 34 samples of colon tumors were collected. All breast cancer patients were operated on including a sentinel lymph node procedure. A total of 12 sigmoid carcinomas, 18 carcinomas of the right hemicolon (including two double carcinomas), and four nonmalignant lesions (one pseudotumor in a patient with chronic diverticulitis and three tubulovillous adenomas) were detected on pathologic analysis.

In the breast cancer group, there were five pT1c and four pT2 tumors. In the colon cancer group, there was one pT1, nine pT2, 18 pT3, and four pT4 tumors, resulting in UICC stage distribution of seven patients with stage I, and ten, eight, and three patients with stage II, III, and IV, respectively [12].

Three patients in the breast cancer group had one or more positive axillary lymph nodes (after sentinel lymph node biopsy, frozen section, and consecutive axillary lymph node dissection), but no patient had known distant metastatic disease at the time of operation (although two were found to have metastases after postoperative restaging). Three patients in the colon cancer group had known metastatic disease at the time of operation, and another was found to have metastases after resection.

In the colon cancer group, 19 patients underwent adjuvant chemotherapy. Seven of nine breast cancer patients were treated with radiation to the remaining breast after tumorectomy and three of these seven patients with additional radiation to the axilla $(\mathrm{pN} 3 \mathrm{a})$. The other four were lymph node-negative on sentinel lymph node biopsy (pN0), and radiotherapy was given routinely after breastconserving treatment. Eight of nine breast cancer patients received adjuvant chemotherapy and/or hormone therapy.

During this pilot study we received systematic feedback from our collaborating pathologists, who confirmed that all specimens, which they received after tissue for fresh frozen banking was removed, were in no way compromised regarding standard histopathology analyses.

The median follow-up time was 610 days (range 10-840 days). It included one patient with colon cancer, who died because of cardiac failure on postoperative day 10. Up to April 2011, no patient was lost to follow-up; nine patients had died, six of whom had no proven cancer recurrence. Three patients died with metastatic disease (two colon cancer patients with lung and liver metastasis, one breast cancer patient with bone metastases).

The total initial costs for tissue banking amounted to 35,662 US\$ (CHF 38,757) (Table 1) [13]. Of these costs, 27,249 US\$ (CHF 29,614) was spent for the
Table 1 Initial and running and costs for tissue banking at a regional hospital

\begin{tabular}{ll}
\hline Acquisition & $\begin{array}{l}\text { Cost } \\
\text { (US\$) }\end{array}$ \\
\hline Initial purchases & \\
SnapFrost isopentan shock freezer & 27,249 \\
Frykavision $-80^{\circ}$ deep freezer & 8,413 \\
Total & $\mathbf{3 5 , 6 6 2}$ \\
Total running costs per annum & \\
Labeling of specimens & 35 \\
PVC specimen bags & 117 \\
Methylbutane for snap freezing $(100.75$ US $\$ / L) \times 5$ & 504 \\
Kryostat O.C.T. embedding solution $(94.31$ US $\$ /$ & 189 \\
125 ml) $\times 2$ & \\
Electricity $(300$ kwh/a) & 55 \\
Transportation $(2 \times / a, 76$ miles) & 166 \\
Dry ice for transportation $(2 \times / a)$ & 184 \\
Total & $\mathbf{1 , 2 5 0}$ \\
Total running costs + investment (during first year) & $\mathbf{3 6 , 9 1 2}$ \\
\hline
\end{tabular}

isopentan-based shock froster, 8,413 US\$ (CHF 9,143) for a $-80{ }^{\circ} \mathrm{C}$ deep freezer, and 1,250 US\$ (CHF 1,358.50) was invested in utility material including isopentan, TissueTek, plastic bags, labeling material, electricity, and transportation costs during the first year (Tables 1, 2). To calculate the cost per sample, we approximated 45 samples/ annum over a period of 10 years, which resulted in a mean cost of $108 \mathrm{US} \$ /$ sample (118 CHF/sample) (Table 2).

\section{Discussion}

To our knowledge, this pilot study is the first report in the literature of fresh frozen tissue banking in a hospital without an integrated institute of pathology. This attempt was initiated by surgical oncologists and proved to be successful.

During the last three decades biobanking and especially fresh frozen tissue banking has been a domain almost exclusively reserved to pathologists. There are numerous reports about successful fresh frozen tissue banks that are run by institutes of pathology in academic centers [7-9, 14-16]. Collaborative networks of these institutions have been founded since the 1990s, such as the Cooperative Human Tissue Network (CHTN) run by the National Cancer Institute in the United States, or the TuBaFrost initiative connecting large local European fresh frozen tissue collections in academic institutions in Spain, The Netherlands, Belgium, United Kingdom, Austria, and France [9, 10]. 
Table 2 Approximate costs per sample after 1-10 years (including investment and running costs) under the assumption of processing 45 samples per annum

\begin{tabular}{|c|c|c|c|c|c|c|c|c|c|c|}
\hline Parameter & DY 1 & DY 2 & DY 3 & DY 4 & DY 5 & DY 6 & DY 7 & DY 8 & DY 9 & DY 10 \\
\hline \multicolumn{11}{|l|}{ Major costs } \\
\hline $\begin{array}{l}\text { Med. Tech. } \\
30 \%\end{array}$ & $\$ 10,698.60$ & $\$ 7,489.02$ & $\$ 5,242.31$ & $\$ 3,669.62$ & $\$ 2,568.73$ & $\$ 1,798.11$ & $\$ 1,258.68$ & $\$ 881.08$ & $\$ 616.75$ & $\$ 431.73$ \\
\hline $\begin{array}{l}\text { Book value } \\
31.12 \text {. }\end{array}$ & $\$ 24,963.40$ & $\$ 17,474.38$ & $\$ 12,232.07$ & $\$ 8,562.45$ & $\$ 5,993.71$ & $\$ 4,195.60$ & $\$ 2,936.92$ & $\$ 2,055.84$ & $\$ 1,439.09$ & $\$ 1,007.36$ \\
\hline $\begin{array}{l}\text { Imputed } \\
\text { interest } 5 \%\end{array}$ & $\$ 534.93$ & $\$ 374.45$ & $\$ 262.12$ & $\$ 183.48$ & $\$ 128.44$ & $\$ 89.91$ & $\$ 62.93$ & $\$ 44.05$ & $\$ 30.84$ & $\$ 21.59$ \\
\hline $\begin{array}{l}\text { Utility } \\
\text { materials } \\
\text { (Table 1) }\end{array}$ & $\$ 1,250.00$ & $\$ 1,250.00$ & $\$ 1,250.00$ & $\$ 1,250.00$ & $\$ 1,250.00$ & $\$ 1,250.00$ & $\$ 1,250.00$ & $\$ 1,250.00$ & $\$ 1,250.00$ & $\$ 1,250.00$ \\
\hline Total & $\$ 12,483.53$ & $\$ 9,113.47$ & $\$ 6,754.43$ & $\$ 5,103.10$ & $\$ 3,947.17$ & $\$ 3,138.02$ & $\$ 2,571.61$ & $\$ 2,175.13$ & $\$ 1,897.59$ & $\$ 1,703.31$ \\
\hline $\begin{array}{l}\text { Costs per } \\
\text { sample } \\
\text { (45/annum) }\end{array}$ & $\$ 277.41$ & $\$ 202.52$ & $\$ 150.10$ & $\$ 113.40$ & $\$ 87.71$ & $\$ 69.73$ & $\$ 57.15$ & $\$ 48.34$ & $\$ 42.17$ & $\$ 37.85$ \\
\hline $\begin{array}{l}\text { Average cost } \\
\text { per sample } \\
\text { over } 10 \text { years }\end{array}$ & $\$ 108.64$ & & & & & & & & & \\
\hline
\end{tabular}

$D Y$ depreciation year

Med Tech $30 \%$ : depreciation of $30 \%$ on book value at the beginning of the year, Book value 31.12.: book value at the end of the year, Imputed interest $5 \%$ : imputed interest on the yearly depreciation with a rate of $5 \%$

One major advantage of fresh frozen tissue banking in a midsized regional hospital is the composition of the study population. Academic centers tend to treat a negative selection of patients in poor condition with multiple comorbidities and advanced-stage disease. This may lead to a relevant selection bias, which can dramatically affect research findings [17-19]. Patients in our study population varied in age and tumor localization but tended to be less affected by multiple co-morbid diseases: $39 \%$ of all patients had only one or no comorbid condition. The distribution of tumor localization and the $\mathrm{T}$ stage were similar to the findings of important epidemiologic studies from cancer registries [20-22].

The present pilot study demonstrates that tissue banking in a regional hospital is feasible, although it comes with a price. Even considering the fact that the freezing and storage devices can be used over a period of 10 years, the costs for one individual sample are high (approximating 45 samples/annum over a period of 10 years would result in $108 \mathrm{US} \$$ sample (118 CHF/sample). In contrast, the amount chargeable to public insurance in Switzerland for a standard histopathologic analysis of a colorectal cancer sample is only 126 US\$ (136.50 CHF) [23]. It seems obvious that additional public and/or private funding is mandatory to be able to offer this auxiliary service.

In the present study, specimen collection by surgical oncologists was safe. However, to achieve this goal we limited eligible tumors to breast and colon cancer only in the present pilot study. For patients with rectal cancer, we considered the risk of interference with standard histopathologic analyses too high because of the importance of proper assessment of the circumferential resection margin in patients undergoing total mesorectal excision [24]. However, we intend, in collaboration with a certified pathologist, to expand the spectrum of malignant diseases to be collected in the future to gastric and pancreatic cancer. For these types of cancer, it is key that a boardcertified pathologist or well-trained resident performs the fresh tissue sampling as it is of prime importance to avoid compromising the quality of the specimens for standard histopathologic analyses.

One area of conflict concerning specimen collection for research purposes by nonpathology residents might be medicolegal concerns. However, the study was approved by the ethics committee of our medical center. Second, the specimen collection was done by pathologist-trained residents, and the quality of our tissue collection was regularly scrutinized by our collaborating pathologists. Third, all patients gave written and verbal informed consent regarding participating in this pilot study. Finally, although it would be interesting to analyze the removed fresh frozen tissue to ensure high quality, it was beyond the scope of the present pilot study.

\section{Conclusions}

This is the first report in the literature that has provided evidence that tissue banking in a regional hospital without an integrated institute of pathology is feasible. However, 
private or public funding is mandatory to perform fresh frozen tissue banking at a regional hospital. The interesting findings of the present pilot study must be corroborated by larger investigations.

Acknowledgments The present pilot project was supported by grants of the Swiss Group for Clinical Cancer Research (SAKK) and the Cancer League of both cantons of Basel, Switzerland. The authors thank Stephanie Loher for her support for follow-up data collection.

Conflict of interest None.

\section{References}

1. Sauter G, Simon R (2002) Predictive molecular pathology. N Engl J Med 347:1995-1996

2. Cardoso F, Piccart-Gebhart M, Van't Veer L et al (2007) The MINDACT trial: the first prospective clinical validation of a genomic tool. Mol Oncol 1:246-251

3. Mook S, Schmidt MK, Weigelt B et al (2010) The 70-gene prognosis signature predicts early metastasis in breast cancer patients between 55 and 70 years of age. Ann Oncol 21:717-722

4. Nuyten DS, Hastie T, Chi JT et al (2008) Combining biological gene expression signatures in predicting outcome in breast cancer: an alternative to supervised classification. Eur J Cancer 44:2319-2329

5. Nuyten DS, Kreike B, Hart AA et al (2006) Predicting a local recurrence after breast-conserving therapy by gene expression profiling. Breast Cancer Res 8:R62

6. Van de Vijver MJ, He YD, van't Veer LJ et al (2002) A geneexpression signature as a predictor of survival in breast cancer. N Engl J Med 347:1999-2009

7. Herpel E, Koleganova N, Schirmacher P (2008) Tissue bank of the National Centre for Tumour Disease: an innovative platform for translational tumour. Pathologe 29(Suppl 2):204-209

8. Knox K, Kerr DJ (2004) Establishing a national tissue bank for surgically harvested cancer tissue. Br J Surg 91:134-136

9. LiVolsi VA, Clausen KP, Grizzle W et al (1993) The cooperative human tissue network: an update. Cancer 71:1391-1394
10. Riegman PH, Dinjens WN, Oomen MH et al (2006) TuBaFrost 1 : uniting local frozen tumour banks into a European network: an overview. Eur J Cancer 42:2678-2683

11. Stege A, Hummel M (2008) Experience with establishment and operation of a biobank. Pathologe 29(Suppl 2):214-217

12. Sobin LH, Wittekind C (2002) TNM classification of malignant tumours, 6th edn. Wiley, New York

13. Credit Suisse AG (2010) Durchschnittsdevisenkurse 2009. https:// www.credit-suisse.com/ch/unternehmen/kmugrossunternehmen/ doc/devisendurchschnittskurse_2009_de.pdf/. Accessed 22 June 2011

14. Chu TY, Hwang KS, Yu MH et al (2002) A research-based tumor tissue bank of gynecologic oncology: characteristics of nucleic acids extracted from normal and tumor tissues from different sites. Int J Gynecol Cancer 12:171-176

15. Leyland-Jones BR, Ambrosone CB, Bartlett J et al (2008) Recommendations for collection and handling of specimens from group breast cancer clinical trials. J Clin Oncol 26:5638-5644

16. Mager SR, Oomen MH, Morente MM et al (2007) Standard operating procedure for the collection of fresh frozen tissue samples. Eur J Cancer 43:828-834

17. Guller U (2006) Surgical outcomes research based on administrative data: inferior or complementary to prospective randomized clinical trials? World J Surg 30:255-266. doi: 10.1007/s00268-005-0156-0

18. Guller $U$ (2008) Caveats in the interpretation of the surgical literature. Br J Surg 95:541-546

19. Imamura K, McKinnon M, Middleton R et al (1997) Reliability of a comorbidity measure: the index of co-existent disease (ICED). J Clin Epidemiol 50:1011-1016

20. Janson M, Edlund G, Kressner U et al (2009) Analysis of patient selection and external validity in the Swedish contribution to the COLOR trial. Surg Endosc 23:1764-1769

21. Gunderson LL, Jessup JM, Sargent DJ et al (2010) Revised TN categorization for colon cancer based on national survival outcomes data. J Clin Oncol 28:264-271

22. O'Connell JB, Maggard MA, Ko CY (2004) Colon cancer survival rates with the new American Joint Committee on Cancer sixth edition staging. J Natl Cancer Inst 96:1420-1425

23. TARMED Suisse (2010). TARMED Version 1.07.00. http:// www.tarmedsuisse.ch/86.html/. Accessed 3 Feb 2011

24. Garcia-Granero E, Faiz O, Flor-Lorente B et al (2011) Prognostic implications of circumferential location of distal rectal cancer. Colorectal Dis 13:650-657 